\title{
Sclerosteosis in a Spanish male: first report in a person of Mediterranean origin
}

\author{
Manuel Bueno, Gonzalo Oliván, Africa Jiménez, Jesús M Garagorri, Antonio Sarría, \\ Antonio L Bueno, Manuel Bueno Jr, Feliciano J Ramos
}

\begin{abstract}
We report the first observation of sclerosteosis in Spain. To the best of our knowledge, this is the first case of sclerosteosis in a person of Mediterranean origin with no known Dutch ancestors. He has the characteristic phenotype of the disease with right facial nerve palsy and syndactyly and the typical radiological features, including generalised bone sclerosis and cortical widening of the tubular bones.
\end{abstract}

(F Med Genet 1994;31:976-977)

Area de Pediatría and
Departmento de
Traumatologia,
Facultad de Medicina,
Hospital Clínico
Universitario “Lozano
Blesa", Universidad
de Zaragoza,
Zaragoza, Spain
M Bueno
G Oliván
A Jiménez
J M Garagorri
A Sarría
A L Bueno
M Bueno Jr
F J Ramos
Correspondence to
Professor M Bueno,
Dpto de Pediatría,
Facultad de Medicina,
Universidad de Zaragoza,
C Domingo Miral s/n,
50009 Zaragoza, Spain.
Received 11 July 1994
Accepted for publication
25 July 1994

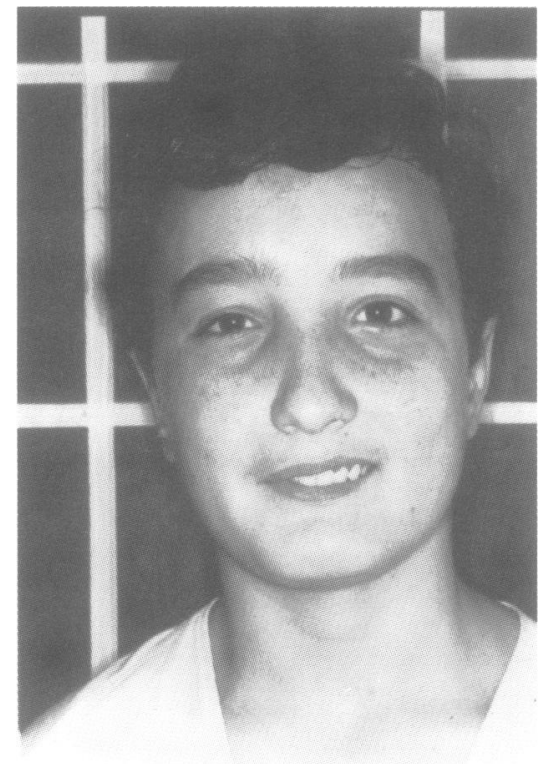

Figure 1 The proband's face aged 12. Note the right facial palsy and prognathism.

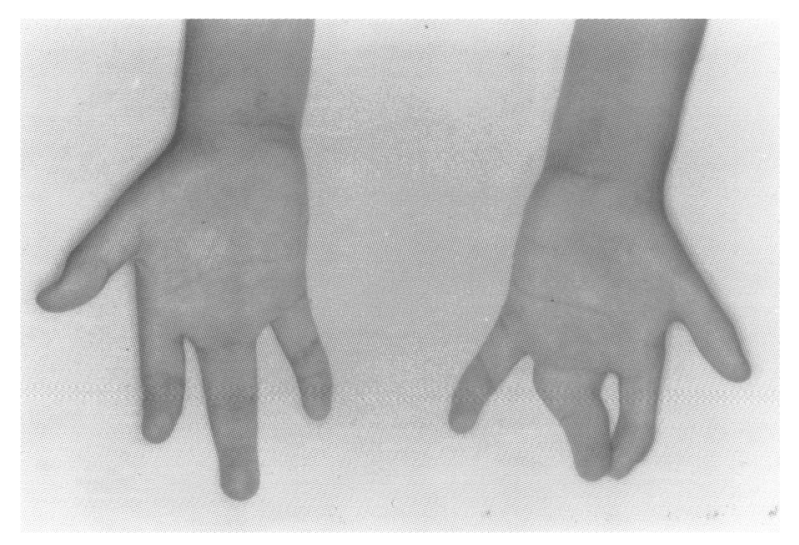

Figure 2 The proband's hands showing bilteral 3-4 syndactyly. The left hand is hypoplastic compared to the right hand.
Sclerosteosis (MIM 269500) is a rare autosomal recessive skeletal dysplasia, included in the group with increased bone density osteochondrodysplasias and the subgroup with endosteal hyperostoses. ${ }^{1}$ The term sclerosteosis was coined by Hansen ${ }^{2}$ in 1967 and since then about 60 cases have been reported, the majority in persons from the Afrikaner community of South Africa. ${ }^{34}$ The few reports from outside South Africa have come from the United States, ${ }^{5-7}$ Japan, ${ }^{8}$ Switzerland, ${ }^{9}$ and Brazil. ${ }^{10}$

Here we describe the first case of sclerosteosis in Spain, a Mediterranean country, in a male with reportedly no Dutch ancestry.

\section{Case report}

The patient, a 12 year 10 month old male, was referred to us for evaluation of a right facial nerve palsy of five months' duration. He is the first and only child of unrelated Spanish parents. The pregnancy and delivery were uncomplicated. At birth he was noticed to have oligodactyly and syndactyly of the hands and bilateral 3-4 syndactyly of the toes. The family history was unremarkable and all family members were natives of Spain with no known Dutch ancestors.

Clinical examination showed a height of $167 \mathrm{~cm}(>97 \%)$ and a head circumference of $59 \mathrm{~cm} \mathrm{(>98 \% ).} \mathrm{He} \mathrm{had} \mathrm{facial} \mathrm{asymmetry} \mathrm{owing}$ to right facial palsy (fig 1), mild frontal bossing, midfacial hypoplasia, dental malocclusion, and marked prognathism. He had oligodactyly with 3-4 syndactyly in both hands (fig 2), the distal portions of some of the fingers were short and radially deviated, and they had hypoplastic nails. He also had mild bilateral 3-4 syndactyly of the toes. No other physical anomalies were found at that time. Intelligence seemed appropriate for his age.

Radiographical findings in the skull included a widened and uniformly sclerotic calvarium with a very dense base (fig 3 ). Other findings were prominent vascular marks, expanded sella turcica, enlarged frontal sinuses, enlarged sclerotic mandible, widened and dense clavicles and ribs, and sclerotic vertebral end plates and pedicles. The sclerotic pelvic bones were not expanded. All long bones were involved and showed cortical hyperostosis with moderate alteration of their external contours. In the hands bilateral 3-4 bony syndactyly with shortening and radial deviation of several phalanges were noted (fig 4). No skeletal anomalies were observed in the toes. CT scan of the head confirmed thickening and sclerosis of the skull diploë, with no evidence of cerebral anomalies or signs of increased intracranial pressure. 


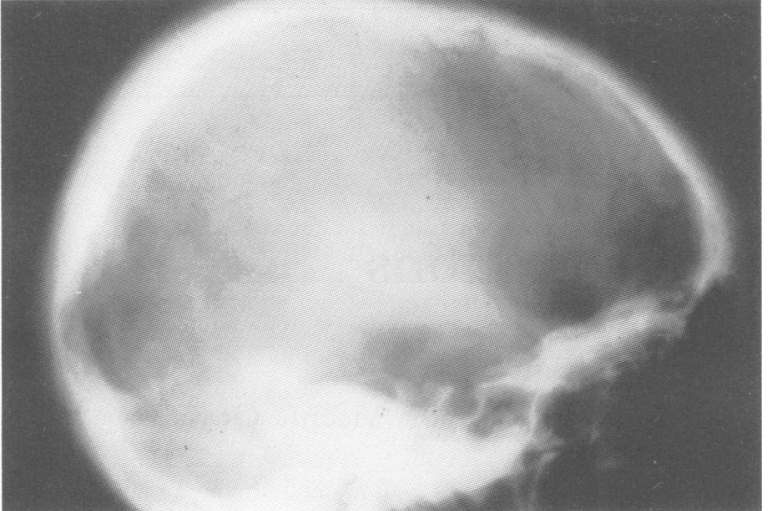

Figure 3 Lateral skull radiograph showing calvarial hyperostosis with marked sclerosis of the cranial base.

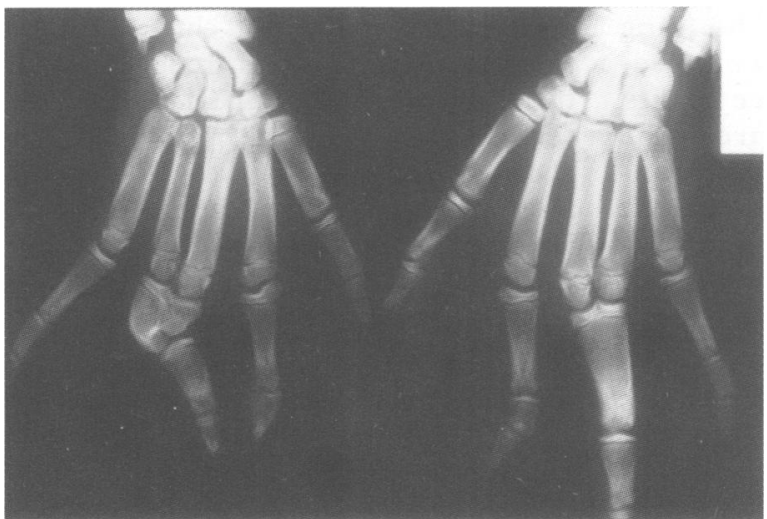

Figure 4 AP radiograph of the hands showing bilateral syndactyly of the third and fourth phalanges, with abnormal bony shape on the right side. Note also radial deviation of terminal phalanges and undermodelled and sclerotic metacarpal tubular bones.

Functional studies, including audiograms, showed intact cranial nerve pairs, except for the seventh pair. Electromyogram and conduction velocity studies of the facial nerve showed basal grouped discharges with a normal reinnervation pattern. Plasma levels of growth hormone (hGH), LHRH, and testosterone were within normal limits, as well as plasma and urine phosphate and calcium.

The patient at the age of 17 is $188 \mathrm{~cm}$ tall $(>97 \%)$ and his head circumference is $60 \mathrm{~cm}$ $(>98 \%)$. Besides his mild right facial palsy he is otherwise asymptomatic.

\section{Discussion}

Sclerosteosis is a rare autosomal recessive disorder and the majority of the cases have been described in the Afrikaner community of South Africa. Affected persons show signs of overgrowth and sclerosis of the bones, especially involving the skull and the facial bones. The anomalies may be present in early childhood and they are progressive. Usually, cranial nerve dysfunction is an early symptom and it is frequently accompanied by tall stature, macrocephaly, prognathism, and distortion of the face. Unlike van Buchem disease, considered an allelic variant of sclerosteosis, persons with sclerosteosis have syndactyly, generally involving the second and third fingers and associated with nail anomalies. ${ }^{10}$

To date, sclerosteosis has been reported in about 60 patients from the Afrikaner (Dutch ancestry) community of South Africa, with a minimum prevalence estimated at about $1 / 60000$ and a gene frequency of $0 \cdot 004 .^{34} \mathrm{In}-$ terestingly, only a few cases have been reported in other countries, including two kindreds in New York and Maryland in the United States, ${ }^{56}$ a 21 year old woman in Japan, ${ }^{7}$ a young woman from Switzerland, ${ }^{8}$ and two relatives from a highly consanguineous Brazilian family of Dutch ancestry. ${ }^{9}$ We report here the first case of sclerosteosis in Spain, a Mediterranean country, in a male who reportedly has no Dutch ancestors. It seems likely that cases of sclerosteosis in persons with no evidence of Dutch ancestry, such as the case of Sugiura and Yasuhara ${ }^{7}$ and our case, could be explained by the random appearance of spontaneous mutations of the sclerosteosis gene in the world population. In their paper, Sugiura and Yasuhara ${ }^{7}$ provide no data about the affected woman's ancestry. It will be very important, once the molecular defect is found, to determine if the mutation is the same in the different populations.

Clinically, our patient has most of the major manifestations of the disease: tall stature, cranial nerve dysfunction (facial palsy), dental malocclusion, prognathism, syndactyly, and generalised hyperostosis and sclerosis of the skeleton, including the skull. At the age of 17, he still has no hearing impairment and no signs of increased intracranial pressure.

In the past, many patients with sclerosteosis were erroneously diagnosed as having AlbersSchönberg disease (osteopetrosis). However, there is now no reason for confusion after excellent clinical descriptions ${ }^{4}$ and its confirmation as a separate entity by the International Working Group on Constitutional Diseases of Bone. ${ }^{1}$

We wish to thank Dr Charles I Scott Jr for his helpful comments on the manuscript.

1 International Working Group on Constitutional Diseases of Bone. International classification of osteochondrodysplasias. Am $\mathcal{F}$ Med Genet 1992;44:223-9.

2 Hansen HG Sklerosteose. In. Opitz H, Schmid F, eds. Handbuch der Kinderheilkunde. Vol 6. Berlin: Springer-VerHandbuch der Kinder

3 Beighton P, Durr L, Hamersma $H$. The clinical features of sclerosteosis. A review of the manifestations in twentyfive affected individuals. Ann Intern Med 1976;84:393-7.

five affected individuals. Ann Intern Med 1976;84:393-7.
Beighton P, Hamersma H. Sclerosteosis in South Africa. $S$ Afr Med $\mathcal{F} 1979 ; 55: 783-8$.

5 Higinbotham NL, Alexander SF. Osteopetrosis. Four cases in one family. Am $\mathcal{F}$ Surg 1941;53:444-54.

6 Stein SA, Wiktop C, Hill S, et al. Sclerosteosis: neurogenetic and pathophysiologic analysis of an American kindship. Neurology 1983;33:267-77.

7 Sugiura Y, Yasuhara T. Sclerosteosis. A case report. 7 Bone foint Surg (Am) 1975;57:273-6.

8 Pietruschka G. Weitere Mitteilungen über die Marmorknochenkrankheit (Albers-Schönbergsche Krankheit) nebst Bemerkungen zur Differential-diagnose. Klin Monatsbl Augenheilkd 1958;132:509-25.

9 Freire de Paes A, Canela JL, Cardoso L, Marcilio $M$ Sclerosteosis: a marker of Dutch ancestry? Rev Brasil Genet 1982;5:825-34

10 Greenspan A. Sclerosing bone dysplasia - a target-site approach. Skeletal Radiol 1991;20:561-83. 